\title{
Estimation of Embodied Energy and Carbon Emissions associated with seismic activities for Reinforced Concrete Building: A Case Study in Iraq
}

\author{
Ali Majdi ${ }^{1}$ | Hasan Sh. Majdi² | AliJabbar Mallooh ${ }^{3}$ \\ 1,2Al-Mustaqbal University College, Babylon, Iraq \\ ${ }^{1}$ Technical University of Civil Engineering of Bucharest, Romania \\ ${ }^{3}$ Construction Authority, Babylon Governorate, Iraq
}

To Cite this Article

Ali Majdi, Hasan Sh. Majdi and AliJabbar Mallooh, "Estimation of Embodied Energy and Carbon Emissions associated with seismic activities for Reinforced Concrete Building: A Case Study in Iraq", International Journal for Modern Trends in Science and Technology, Vol. 06, Issue 07, July 2020, pp.:30-36; https://doi.org/10.46501/IJMTST060705

Article Info

Received on 11-June-2020, Revised on 18-June-2020, Accepted on 21-June-2020, Published on 29-June-2020.

\section{ABSTRACT}

The sustainable building construction in last decade is trending in the world. The construction process of each material used for erection the buildings consumes energy and causes $\mathrm{CO} 2$ emissions. The developed countries consider the determination of the energy embodied (EE) in building materials and the related $\mathrm{CO} 2$ or carbon emissions (CE) is one of the main aspect in the evaluation of the performance of the buildings. The damages that caused by earthquake and their related repair activities caused a wide range of environmental impacts. These impacts correlated with building construction and repair are typically quantified using environmental life cycle assessment (LCA) procedures that developed by American applied technology council (ATC). FEMA P-58 methodology -which prepared by ATC- applies this procedure in order to estimate environmental impacts of damage and repair using two metrics: carbon emissions $C E$ (in units of $\mathrm{kg}$ of carbon dioxide equivalents emitted, CO2e) and embodied energy $E E$ use (in units of Mega Joules, MJ). This paper uses FEMA P-58 to evaluate the embodied energy and the related CO2 emissions of building materials for a case study building in AL-Mustaqbal University College in Al-Hilla City in the middle of Iraq. The study is a continuation of other research papers related to applying the same approach on the same building that the researcher undertook for the purpose of evaluating the performance of the building when exposed to earthquake and calculating the economic and social losses.

KEYWORDS: Building, FEMA P-58, Environmental Impacts, Carbon Emissions, Embodied Energy, Life Cycle, LCA, PACT, Buildings in Iraq

Copyright ( 2014-2020 International Journal for Modern Trends in Science and Technology

DOI: https://doi.org/10.46501/IJMTST060705

\section{INTRODUCTION}

The International Energy Agency (IEA) reported that the Global building stock emissions continue to rise. In 2018, global emissions from buildings increased $2 \%$ for the second consecutive year to 9.7 gigatonnes of carbon dioxide ( $\mathrm{GtCO} 2)$, buildings and construction sector causes $36 \%$ of final energy use and 39\% of energy and process-related carbon dioxide (CO2) emissions in 2018, 11\% of which resulted from manufacturing building materials and products such as steel, cement and glass. As shown in figures 1 and 2 [1]

The construction industry uses most of raw materials by weight than any other industrial 
sector. About $50 \%$ of all materials extracted from the Earth's crust are processed into construction materials [2].The consumption of energy produces $\mathrm{CO} 2$, which contributes to greenhouse gas emissions, so embodied energy is considered an indicator of the overall environmental impact of building materials and systems, it is measured as the quantity of non-renewable energy per unit of building material, component or system [3]

The prediction and quantifying of the potential earthquake damages for a specific building enables estimating its environmental impacts by using life cycle assessment LCA procedure. This procedure provides comprehensively measuring -using a set of metrics- of the environmental impacts of buildings over their full life cycle.

Cabeza et al. [4] reported that embodied energy represents $10-20 \%$ of a building's lifecycle energy

The International Standards Organization (ISO) provides guidelines for LCA of the building, ISO 14044 procedures (ISO, 2006a; ISO, 2006b) is a standard, in which buildings are taken as large products with long and uncertain lives. LCA can utilize one of several methods or models in order to completing the environmental impact assessments, including a unit process method, an economic input-output (EIO) method, or a hybrid method that combines aspects of the both approaches. The European Committee for Standardization (ECS) provides CEN/TC350 Sustainability of construction works for the assessment of the sustainability aspects of new and existing construction works (buildings and civil engineering works), including standards for the environmental product declaration of construction products (EPD) [5].

The FEMA P-58 methodology is developed by ATC to predict probable earthquake damages and socio-economic consequences in terms of repair costs, casualties, and loss of use due to repair time or unsafe placarding. The method is expanded to assess probable environmental impacts associated with earthquake damage and repairs, these impacts are presented by carbon emissions $\mathrm{CE}$ and

embodied energy EE by using LCA procedure.
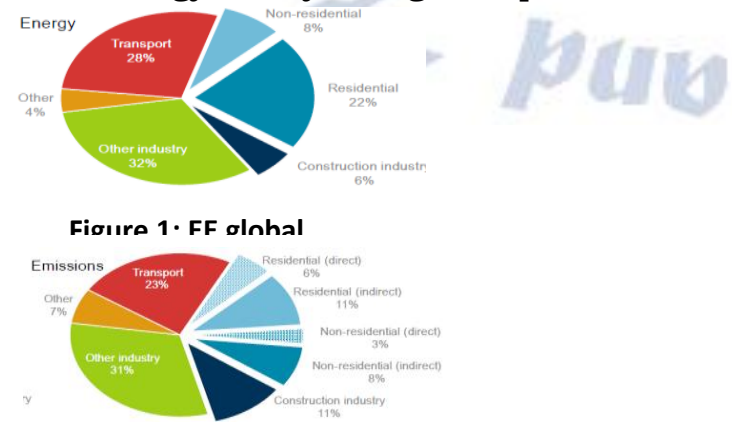

Figure 1: CE Global

\section{CE AND EE IN IRAQ}

In Iraq, like in most of developing countries, the considering of embodied energy $\mathrm{EE}$ and carbon emissions $\mathrm{CE}$ for construction sector is almost neglected. According to Worldmeter, the $\mathrm{CO} 2$ emissions in Iraq increased in last decade as shown in Figure 3 [6], fossil $\mathrm{CO} 2$ Emissions in 2016 were 162,646,160tons[6]. [In the research field, some researchers began in recent years to conduct studies that are concerned with this important scientific discipline. Hasan and Jassim [7] studies by using FEM the effect and the role of multi-story structural building systems on reducing embodied energy consumption and carbon emissions in Iraq. They found that the reinforced concrete building consumed less embodied the energy and carbon emissions, in compare with the buildings constructed from pre-cast concrete and steel structurers. Ibrahim et al. tried [8] investigated the current problems of the built environment in the Kurdistan region in Iraq, especially regarding energy consumption, in addition the researchers provided regulations to restrict building guidelines in accordance with sustainable concept to reduce energy consumption of built environment. Abbood et al. [9] suggested applying the industrialization approaches of Industrial Building System (IBS) for residential buildings in Iraq in order to achieve the energy efficiency in the building industry of the country. They compared the level of energy efficiency in the conventional system and IBS using FEM and they found that IBS can reduce the annual energy consumption of $37.32 \%$ for heating and $65.36 \%$ for cooling. Based on the previous studies and similar studies, most of researches focus on the energy efficiency in the built environment, the embodied energy during the construction and repair of the buildings and other structures and its related carbon emissions is new discipline in Iraq. The embodied energy could be defined as the total energy required for the extraction, processing, manufacture and delivery of building materials to the building site.

\section{Iraq CO2 emissions by Year (tons)}

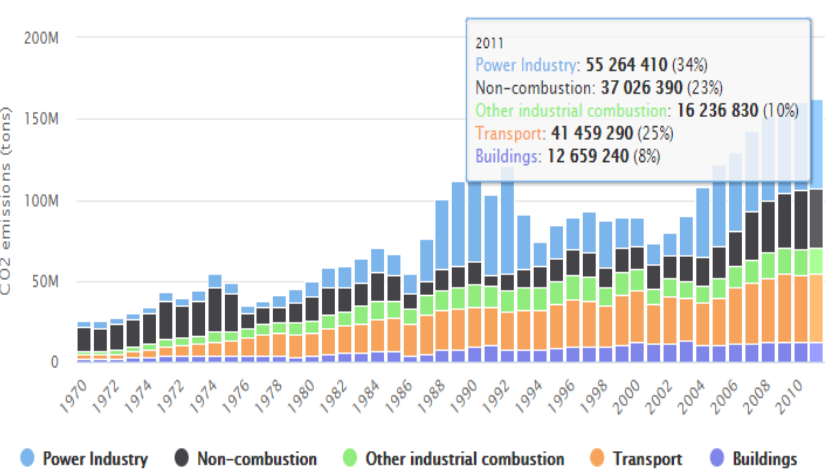

Figure 2: Iraq $\mathrm{CO}$ emissions by Year (tons) [6] 


\section{Methodology}

The calculating of $\mathrm{CE}$ and $\mathrm{EE}$ emissions is complex and consist of numerous sources of data. FEMA P-58 methodology involves environmental life cycle assessment (LCA) procedures in order to quantify the environmental impacts (EE and $\mathrm{CE}$ ) associated with building construction and repair. In this methodology, Economic Input Output LCA (EIO-LCA) data are used to estimate environmental impacts of damage and repair using two metrics: embodied carbon (in units of $\mathrm{kg}$ of carbon dioxide equivalents emitted, $\mathrm{CO} 2 \mathrm{e}$ ) and embodied energy use (in units of Mega Joules, MJ) [10].

These impacts are calculated directly from the total repair cost estimates with the generalized EIO impact per dollar spent in each sector or occupancy of the building, multiplied by the repair costs in each of these sectors. Thus, the level of precision parallels the level of precision in the repair cost estimate. The range and uncertainty of environmental impacts are estimated to match the range and uncertainty in the repair costs [11].

FEMA P-58 presents the environmental impacts in terms of $\mathrm{CE}$ and $\mathrm{EE}$, to restore the building to its pre-earthquake condition, or to replace it with a new one with similar construction in the case of total collapse. In this paper an Intensity-Based Performance Assessment Using Simplified Analysis is applying to calculate the $\mathrm{CE}$ and $\mathrm{EE}$ for each intensity level depends on the performance groups. These groups are collected from structural and nonstructural components of the building following the procedure of FEMA P-58 methodology.

Eight ground shaking intensities for Structural analysis results are input and twelve ground motions for each intensity level. Following the methodology procedure, each demand vector, related with one ground motion includes input for floor acceleration and peak story drift at each level in each direction and maximum residual story drift.

\section{Summary OF CASE STUdy BUILDING}

The selected building is a four storey reinforced concrete building that described in details by the author Majdi [12] and the basic data listed in table 1 and floor plan illustrated in figure

Table 1: Basic information of case study building

\begin{tabular}{lcc}
\hline Description & Quantity & Dimensions (m) \\
\hline Spans & 4 & 20 \\
\hline Bays & 3 & 15 \\
\hline Stories & 4 & 3 \\
\hline Ground level & 1 & 2.5
\end{tabular}

Floors area, height and occupancy

No $\quad$ Floor Area $\left(\mathbf{m}^{2}\right) \quad$ Height $\quad$ occupancy

\begin{tabular}{ccccl}
\hline 1 & GF & $\mathbf{3 0 0}$ & 2.5 & $\begin{array}{l}\text { Documentation } \\
\text { and archive }\end{array}$ \\
\hline 2 & $\begin{array}{c}1^{\text {st }} \\
\text { floor }\end{array}$ & $\mathbf{3 3 0}$ & 3 & $\begin{array}{l}\text { Student } \\
\text { registration } \\
\text { and waiting } \\
\text { area }\end{array}$ \\
\hline 3 & $2^{\text {nd }}$ & $\mathbf{3 7 5}$ & 3 & $\begin{array}{l}\text { Place of } \\
\text { studies and } \\
\text { research unit } \\
\text { floor }\end{array}$ \\
& & & \\
\hline
\end{tabular}

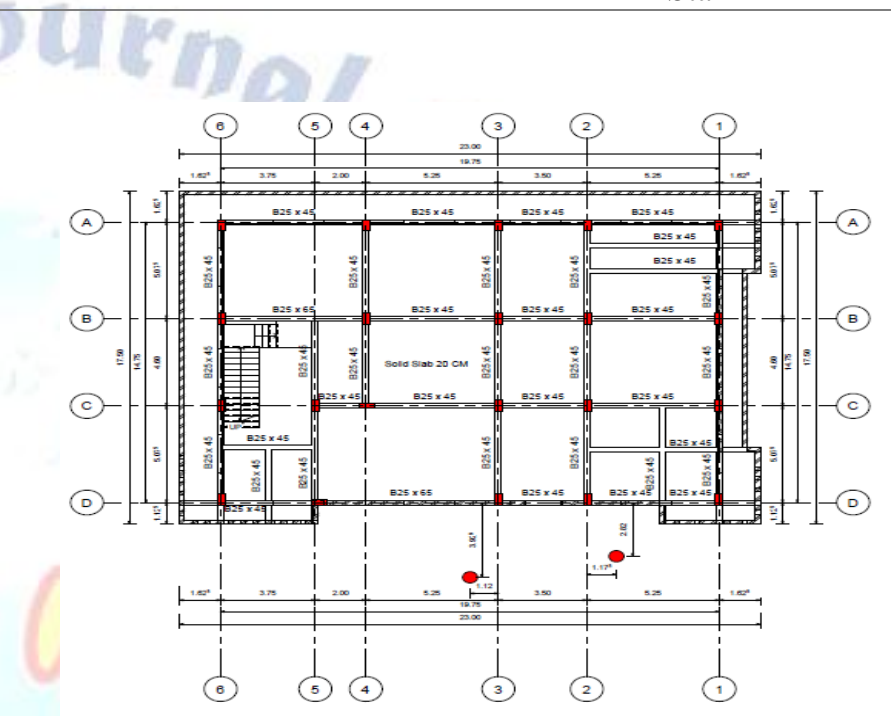

Figure 4: Floor plan of the building

$\begin{array}{ccccc}3^{\text {rd }} & \mathbf{3 7 5} & 3 & \begin{array}{l}\text { Accounting } \\ \text { floor }\end{array} & \\ & & \text { and Human } \\ & \text { resources }\end{array}$

The estimated main costs of the case study building are listed in table 2 .

Table 2: Estimated costs of the case study building

\begin{tabular}{lr}
\hline Cost USD $/ \mathrm{m}^{2}$ & 420 \\
\hline Core and Shell replacement per USD $/ \mathrm{m}^{2}$ & 280 \\
\hline Total replacement cost USD & 579600 \\
\hline Core and Shell replacement USD & 386400
\end{tabular}

\section{ENVIRONMENTAL IMPACTS}

Environmentalimpact of a product is characterized as "embodied" it does not mean that it is really embodied in the product itself. It is used in a metaphorical sense to describe the impacts caused by life cycle stages of a product other than the operation5 (embodied in a virtual sense). It can also be seen as a result of an allocation of energy and material flows to a product or service [13].

The environmental impacts $\mathrm{CE}$ and $\mathrm{EE}$ are estimated by generated directly from the repair cost estimates in collaboration between construction cost amount and related with environmental factors. These factors of the environmental impact 
are extracted from United States Environmentally Extended Input-Output (USEEIO) database [14]. The data base includes replacement cost by the appropriate construction sector impacts from the United States Environmentally Extended Input-Output (USEEIO) database [14].
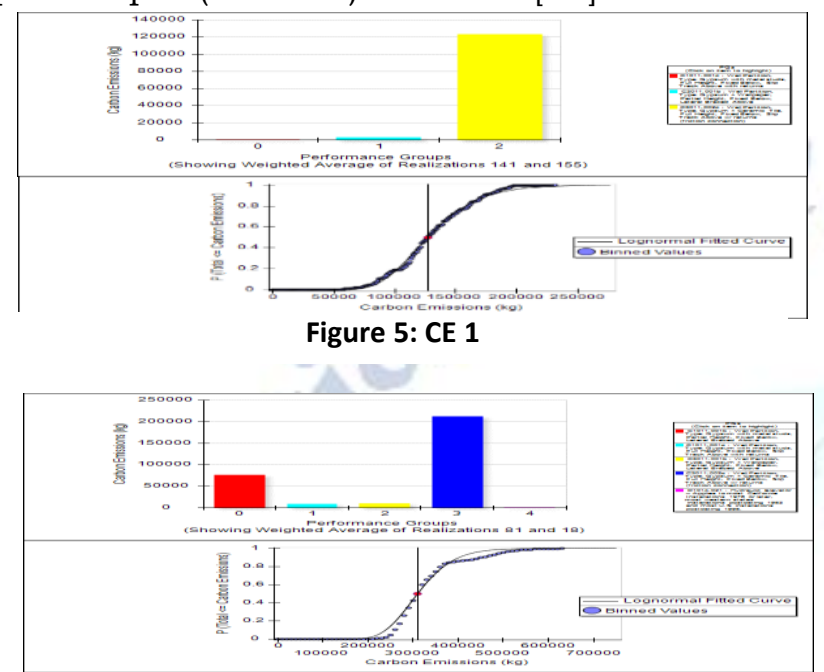

Figure 6: CE 2

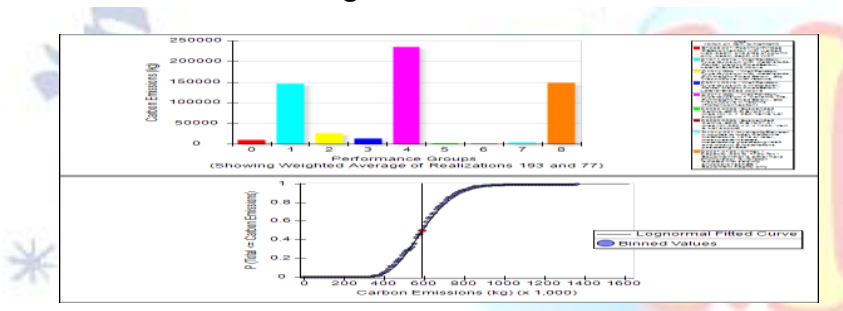

Figure 7: CE 3

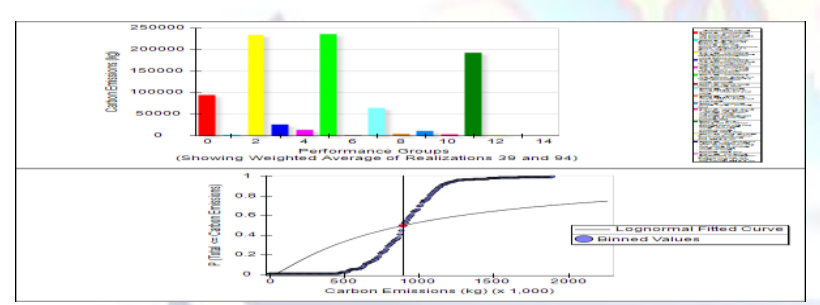

Figure 8: CE 4

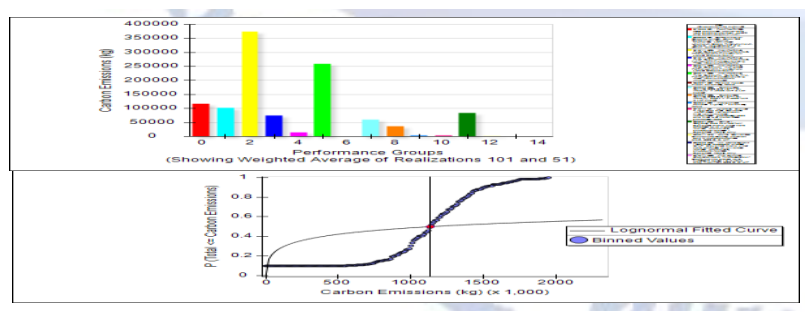

Figure 9: CE 5

The Carbon Emissions Replacement according to FEMA P-58 is the total carbon impact of replacing the building. This is calculated by multiplying the Total Replacement Cost by the appropriate construction sector impacts from the United States Environmentally Extended Input-Output (USEEIO) database.

Mathematically,
$\mathrm{CE}=\frac{\mathrm{TC} * \mathrm{GWP}}{\mathrm{IF}}$

Where:

$\mathrm{CE}=$ The total Carbon Emissions impact of replacing the building, Units

$\mathrm{TC}=$ Total replacement cost for the building, in USD

GWP = global warming potential, taken from USEEIOv1.1_Matrices and depend on the occupancy of the building

$\mathrm{IF}=$ inflation factor, depend on Inflation rate in Iraq, assumed 1 , because there is no significant change in economic situation in Iraq.

Theresulting carbon emissions impact of building replacement would be $(0.354 \mathrm{~kg} \mathrm{CO} 2 \mathrm{e} / \$)$ $\times(\$ 579,600) /(1.0)=204,921 \mathrm{~kg} \mathrm{CO} 2 \mathrm{e}$.

Embodied Energy (EE)

$$
\mathrm{EE}=\frac{\mathrm{TC} * \mathrm{EI}}{\mathrm{IF}}
$$

Where:

$\mathrm{EE}=$ The total embodied energy impact of replacing the building, Units

$\mathrm{TC}=$ Total replacement cost for the building, in USD

$\mathrm{EI}=$ Energy Impact, taken from USEEIOv1.1_Matrices and depend on the occupancy of the building (labeled in the dataset as "resource use/enrg/mj")

IF = inflation factor, depend on Inflation rate in Iraq, assumed 1.

the resulting energyemissions of building replacement would be $(5.789 \mathrm{MJ} / \$) \times(\$ 579,600) /(1.0)=3,407,705$ MJ.

\section{Results}

The following results of $\mathrm{CE}$ and $\mathrm{EE}$ are obtained from PACT software after input all data of the building and ground motion shaking applying a simplified analysis method.

Figures 5 to 12 provides illustrative results from PACT analysis for each intensity level for $\mathrm{CE}$ and figures 13 to 20 for $\mathrm{EE}$. At the bottom of each figure, the estimated $\mathrm{CE}(\mathrm{EE})$ median emissions in $\mathrm{kg}$. The top half of the figure can be used to identify the contribution of different performance groups to the carbon emissions. 


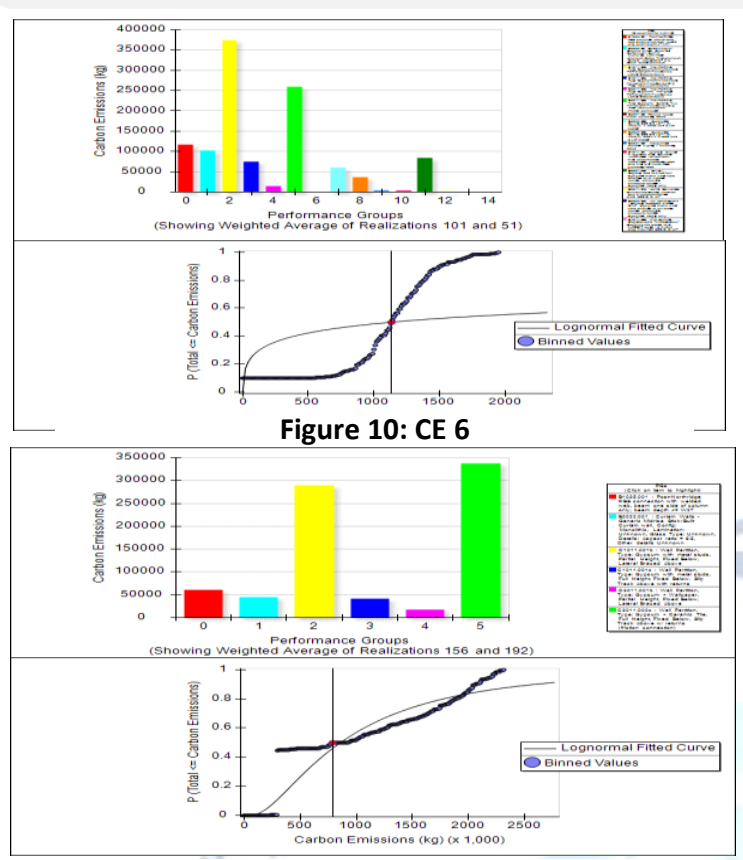

Figure 11: CE 7

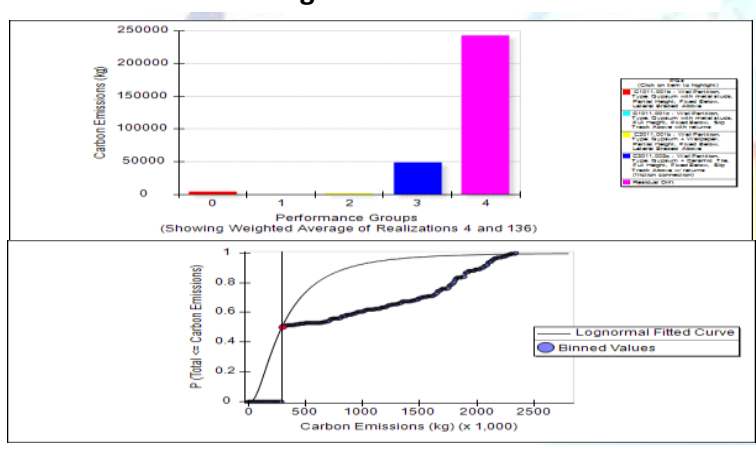

Figure 12: CE 8

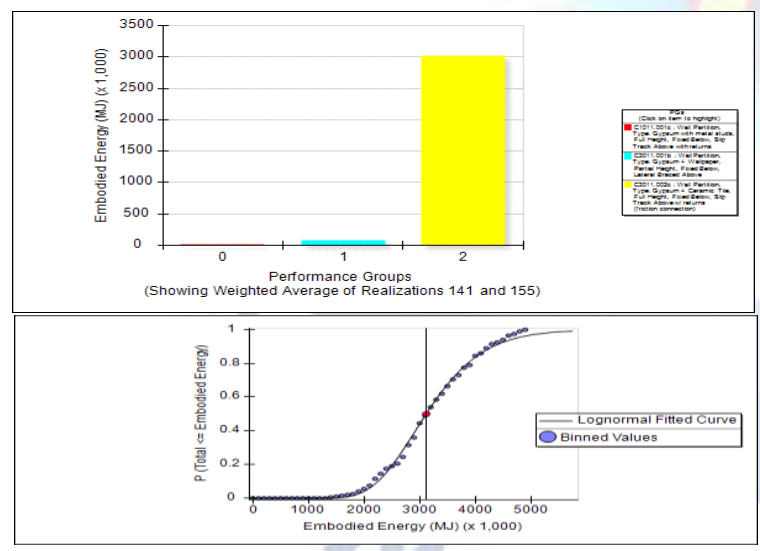

Figure 13: EE1

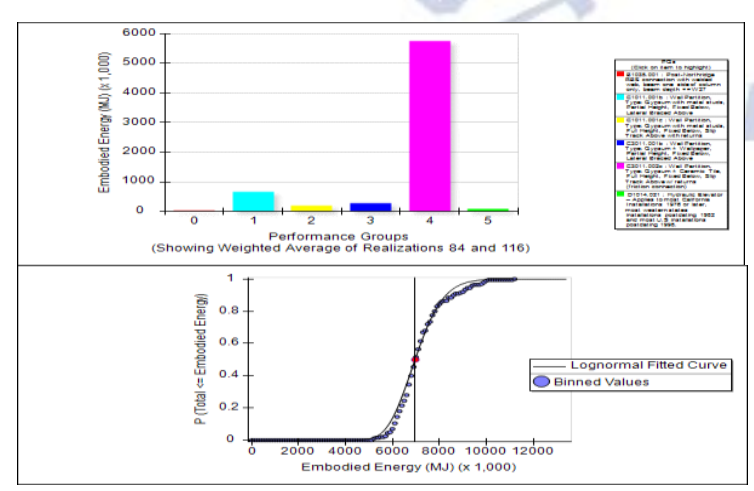

Figure 14: EE 2

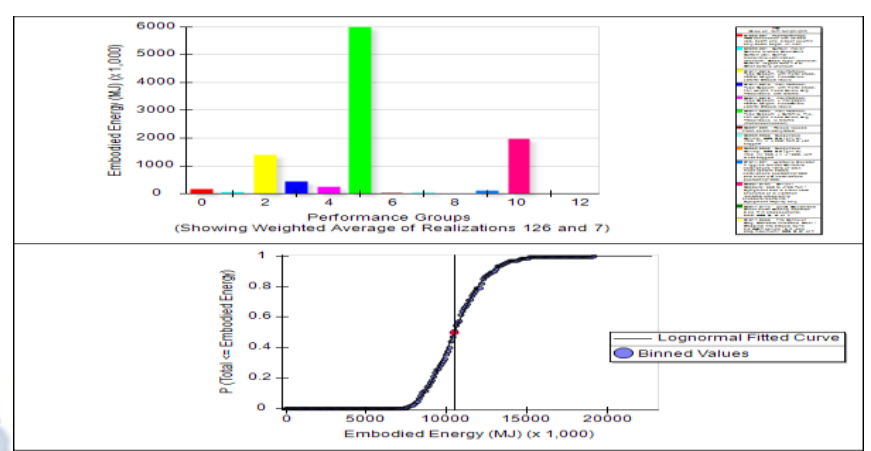

Figure15: EE 3

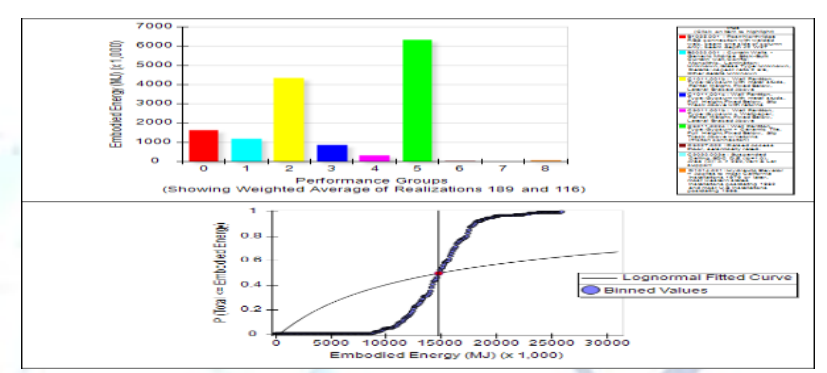

Figure 16: EE 4

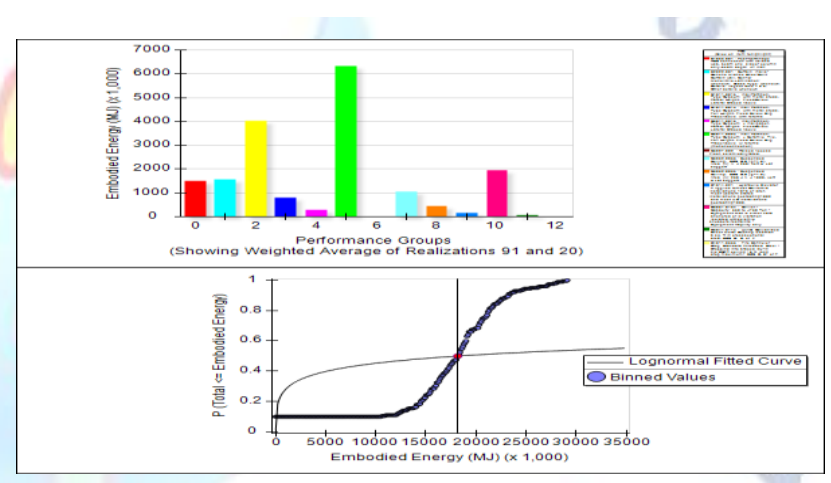

Figure 17: EE 5

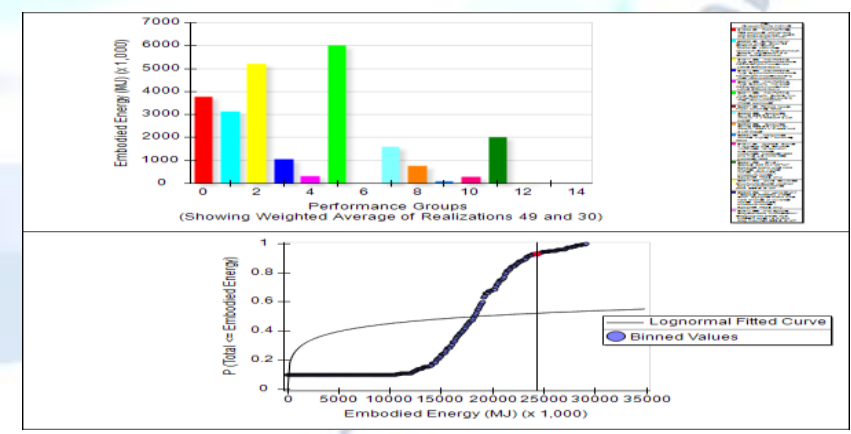

Figure 18: EE 6

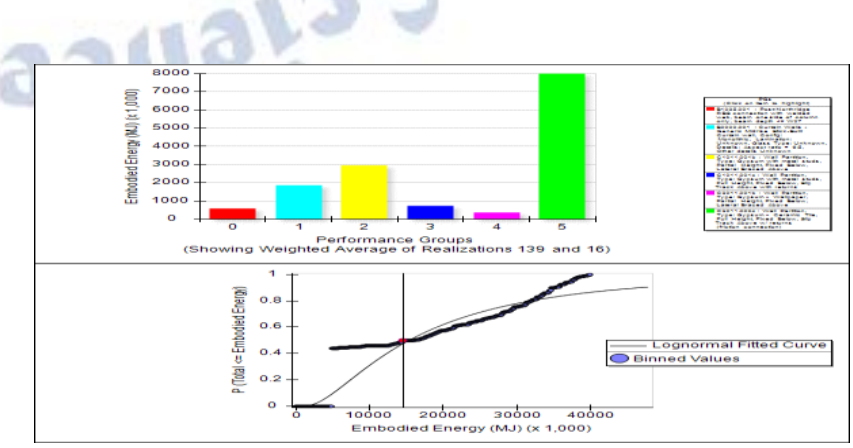

Figure 19: EE 7 


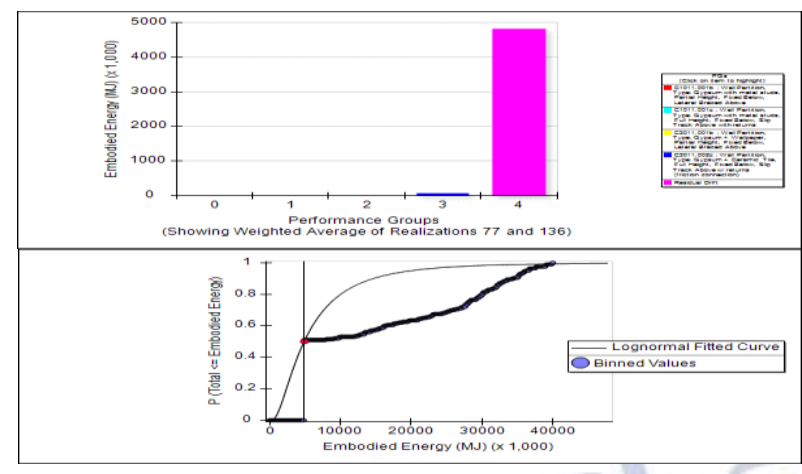

Figure 20: EE 8

Figures 21 and 22 illustrates the average value of loss, per year, over a period of many years, which represent the values of annualized $\mathrm{CE}$ and $\mathrm{EE}$. Figures 22 and 23 shows area chart for CE and EE respectively

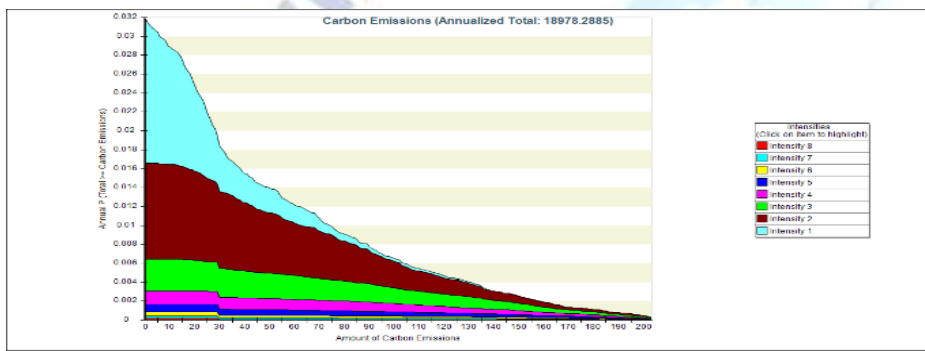

Figure 21: CE annualized

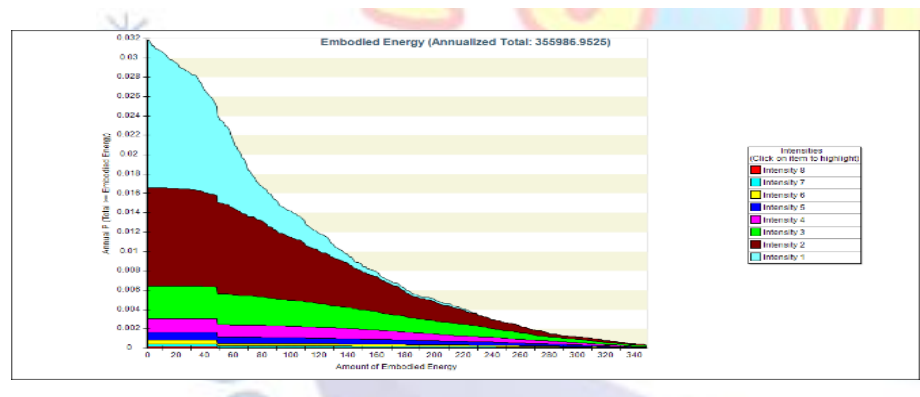

Figure 22: EE annualized

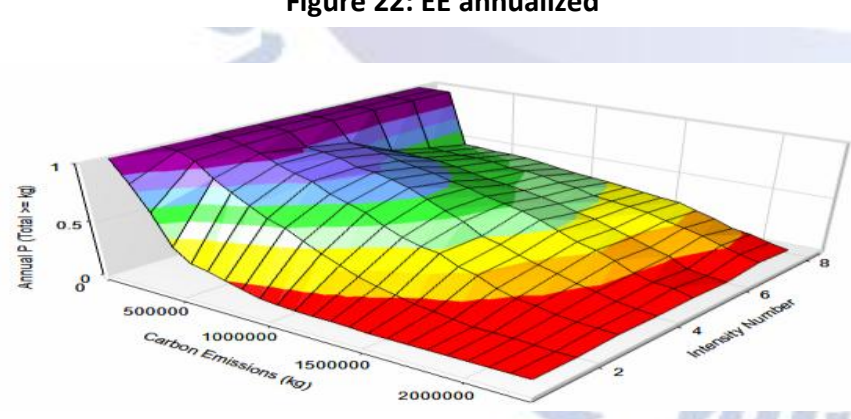

Figure 233: CE area chart

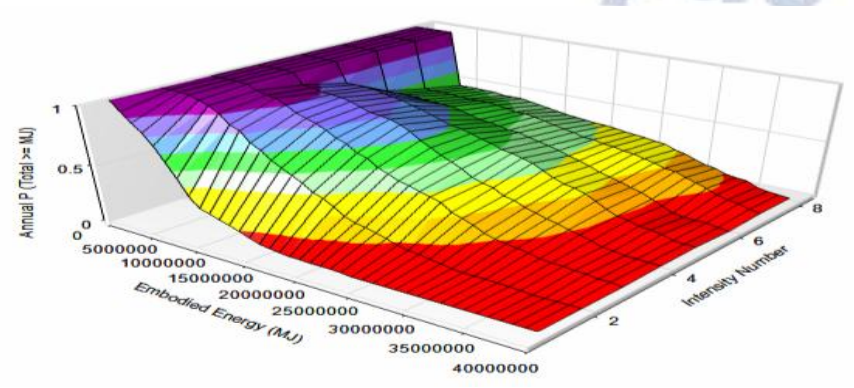

Figure 24: EE area chart

\section{Conclusion}

In this report FEMA P-58 methodology is used in order tocalculate the environmental impacts of reinforced concrete building, in terms of carbon emissions and embodied energy after earthquake. The resulted values of these impacts represent the $\mathrm{CE}$ and $\mathrm{EE}$ that required to restore the building to its pre-earthquake condition in case of the building is repairable after the seismic action, or in the case of total loss, to replace the building with a new structure of similar construction. $\mathrm{CE}$ and $\mathrm{EE}$ values are quantified using environmental life cycle assessment (LCA) procedures and depends on total replacement cost, inflation factor and related coefficient that obtained from USEEIO database. The values obtained were $204,921 \mathrm{~kg}$ CO2e and 3,407,705 MJ for CE and EE respectively.

These values are putted in PACT software with other important data such as building information, ground motion selection, intensity levels, estimated cost of the building and etc. in order to perform the analysis.

The results that obtained could be highlighted as following:

- The carbon emissions are varying according to performance group; PACT use the same approach of worse case in all realizations for each intensity. The annualized total is 18978 $\mathrm{kg}$.

In the similar manner of carbon emissions, the annualized total of embodied energy is $355986 \mathrm{MJ}$.

\section{REFERENCES}

[1] 2019 Global Status Report for Buildings and Construction. United Nations Environment Programme, 2019, ww.worldgbc.org/sites/default/files/2019\%20Global\%20 Status\%20Report $\% 20$ for\%20Buildings\%20and\%20Constr uction.pdf.

[2] Torgal, F.P.; Jalali, S. Eco-E_cient Construction and Building Materials; Springer-Verlag London Limited: London, UK, 2011.

[3] "What Is Embodied Energy in Building?" Level. The Authority on Sustainable Building., July 19, 2019. http://www.level.org.nz/material-use/embodied-energy/.

[4] Cabeza, L.F.; Rincón, L.; Vilariño, V.; Pérez, G.; Castell, A. Life cycle assessment (LCA) and life cycle energy analysis (LCEA) of buildings and the building sector: A review. Renew. Sustain. Energy Rev. 2014, 29, 394-416.

[5] European committee for standardization. (2018). CEN/TC 350 - Sustainability of construction works. Retrieved June 22, 2020, from https: / / standards.cen.eu/dyn/www/f?p=204\%3A7\%3A0 \%3A\%3A\%3A\%3AFSP_ORG_ID\%3A481830

[6] "Iraq CO2 Emissions." Worldometer, September 10, 2019. https://www.worldometers.info/co2-emissions/iraq-co2-e missions/.

[7] Hassan, S. A., \& Jassim, J. A. (2019). The role of multi-story structural building systems on reducing embodied energy consumption and carbon emissions. IOP

35 International Journal for Modern Trends in Science and Technology 
Conference Series: Materials Science and Engineering, 518, 022031. doi:10.1088/1757-899x/518/2/022031

[8] Ibrahim, Rojhat. K., Hariwan N. Zebari, and Haval A. Abdulkareem. "Potential of Energy Conservation in Residential Building Regulations - Kurdistan, Iraq." Procedia Environmental Sciences 34 (2016): 506-13. https://doi.org/10.1016/j.proenv.2016.04.044.

[9] Abbood, Ammar W., Karam M. Al-Obaidi, HanizamAwang, and Abdul Malek Abdul Rahman. "Achieving Energy Efficiency through Industrialized Building System for Residential Buildings in Iraq." International Journal of Sustainable Built Environment 4, no. 1 (2015): 78-90. https://doi.org/10.1016/j.ijsbe.2015.02.002.

[10] Seismic Performance Assessment of Buildings, Volume 1 Methodology. ATC applied technology council, CA ,USA 2018.

[11] Seismic Performance Assessment of Buildings, Volume 2 -Implementation Guide. applied technology CA ,USA, 2018.

[12] Majdi, A. (2020). Applying ATC FEMA P-58 Approach and Nonlinear History Analysis to Estimate Economic and Social Losses due Earthquake for Reinforced Concrete Building in Iraq. International Journal of Innovative Science and Research Technology, 5(4). Retrieved April, 2020,

from https://ijisrt.com/applying-atc-fema-p58-approach-and-n onlinear-history-analysis-to-estimate-economic-and-social -losses-due-earthquake-for-reinforced-concrete-building-i n-iraq

[13] International Energy Agency Evaluation of Embodied Energy and CO2eq for Building Construction (Annex 57) Subtask 1: Basics, Actors and Concepts September 2016

[14] U.S. EPA Office of Research and Development (ORD). "USEEIO v1.1 - Matrices." EPA.Environmental Protection Agency, July 14, 2017. https://edg.epa.gov/metadata/catalog/search/resource/ details.page?uuid=https $\% 3 \mathrm{~A} \% 2 \mathrm{~F} \% 2 \mathrm{Fdoi}$. org $\% 2 \mathrm{~F} 10.23719$ $\% 2 \mathrm{~F} 1369615$.

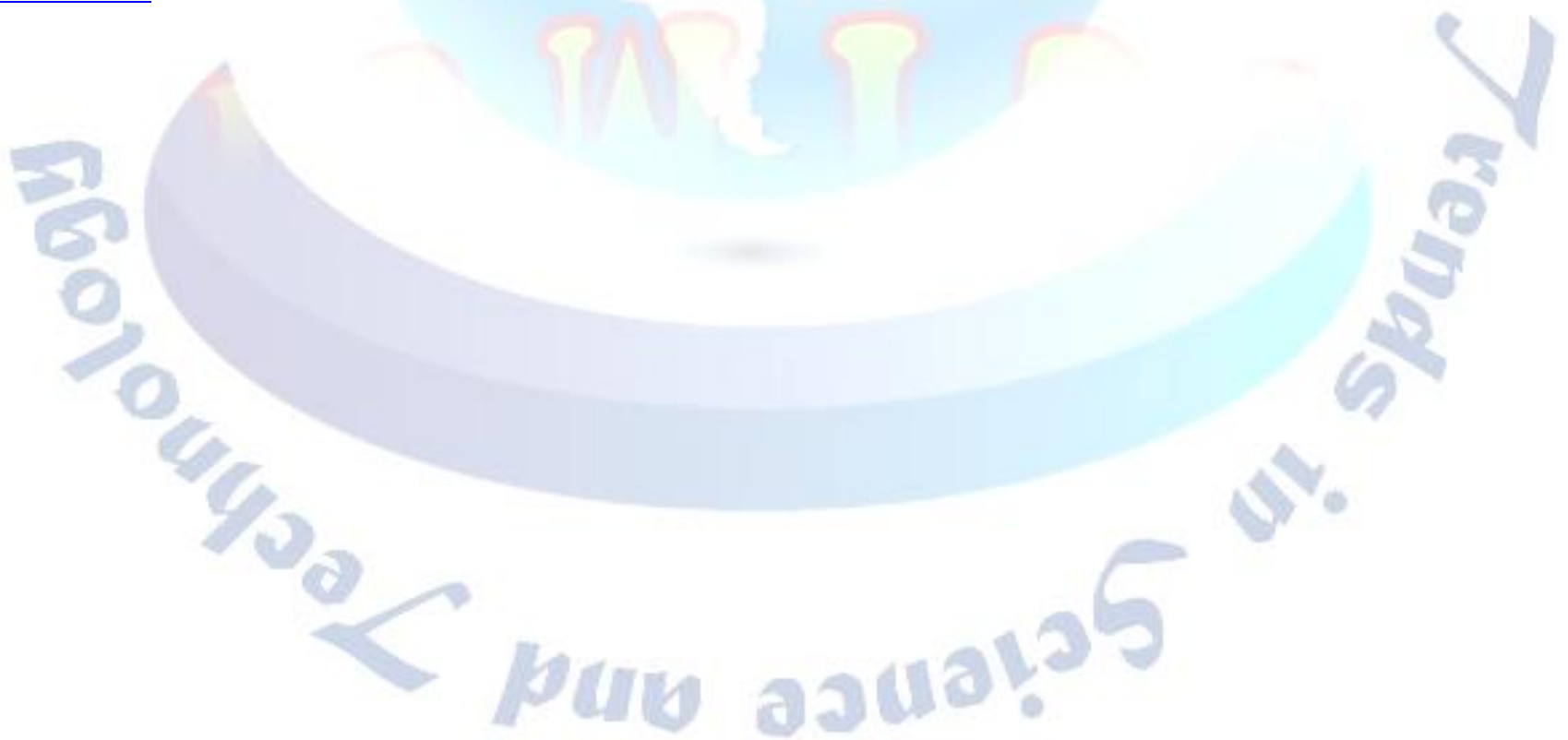

